\title{
Simple HPLC Evaluation of Lipoamidase Activity in Tissue Using a Newly Synthesized Fluorescent Substrate, Dansyl- $\alpha$-lipoyllysine
}

\author{
Rouhollah MOTAFAKKERAZAD ${ }^{1}$, Man-yuan WANG $^{2,3}$, Naoki WADA ${ }^{4}$, \\ Seiichi MATSugo ${ }^{1,4, *}$ and Tetsuya KonISHI ${ }^{2}$ \\ ${ }^{1}$ Graduate School of Natural Science and Technology, Kanazawa University, Kanazawa 920-1192, Japan \\ ${ }^{2}$ Faculty of Applied Life Sciences, Niigata University of Pharmacy and Applied Life Sciences, \\ Niigata 956-8603, Japan \\ ${ }^{3}$ School of Traditional Chinese Medicine, Capital Medical University, Beijing 100069, P. R. China \\ ${ }^{4}$ School of Natural Systems, College of Science and Engineering, Kanazawa University, \\ Kanazawa 920-1192, Japan
}

(Received April 4, 2011)

\begin{abstract}
Summary $\alpha$-Lipoic acid (LA) is a naturally occurring disulfide-containing compound used as an antioxidant supplement which also has been used as a medicine for diabetic neuropathy in Europe. Physiologically LA acts as a coenzyme of mitochondrial multienzyme complex in its protein bound form but it is not yet clear how the externally administrated LA is incorporated into other proteins in the same protein-bound form or why the bound form is active as an antioxidant. The binding and cleavage of LA to or from the protein is mediated by lipoamidase and thus determines LA distribution in tissues. We have developed a simple sensitive assay for lipoamidase using a fluorescent substrate, dansyl- $\alpha$-lipoyllysine (DLL). Lipoamidase in tissues cleaves the amide bond between LA and the $\varepsilon$-amino-lysine moiety to release dansylated lysine (DL). A HPLC comparison of the fluorescence intensity between DLL and DL was used to quantify the enzyme activity. The hydrolytic reaction did not occur when the tissue was heat-treated before incubation with DLL and was inhibited by free LA, especially by the R-enantiomer of LA (physiologically active form). $N_{\varepsilon}$-Acetyl-Llysine did not compete with DLL in the cleavage reaction. The method was applied for the determination of lipoamidase activity levels in various rat tissues. It was revealed the spleen had the highest activity followed by the kidney, heart, lung and liver. The activity in the brain was below the detection limit of the assay.
\end{abstract}

Key Words lipoamidase, lipoic acid, dansyl- $\alpha$-lipoyllysine, HPLC, fluorescent assay

$\alpha$-Lipoic acid (LA) is a naturally occurring disulfidecontaining compound known as 6,8-thioctic acid, 5(1,2-dithiolan-3-yl)-pentanoic acid or 1,2-dithiolane-3valeric acid (1). There are two enantiomers, R- (the naturally occurring type) and S-LA. LA occurs widely in nature and functions as an essential cofactor of the mitochondrial multienzyme complex: pyruvate dehydrogenase, $\alpha$-ketoglutarate dehydrogenase, branchedchain $\alpha$-keto acid dehydrogenase, and the glycine cleavage enzyme systems. In these enzymes, LA is present in the protein-bound form through an amide linkage with the $\varepsilon$-amino group of lysine residues (2-7). Proteinbound LA is high in such tissues as the heart, liver and kidney $(8)$ as they all contain a high population of mitochondria. LA is also widely distributed in plants including fruits and vegetables such as spinach, broccoli, tomatos, garden peas, Brussels sprouts and rice bran (9) in diverse amounts.

The antioxidant properties of free LA attracts much

*To whom correspondence should be addressed.

E-mail: matsugoh@t.kanazawa-u.ac.jp attention because of its unique redox potential and metal chelating functions (1), although it is still unclear whether protein-bound LA is active as an antioxidant. Both LA and its reduced form, dihydrolipoic acid (DHLA), have the potential to scavenge various types of ROS, free radicals and other oxidants. Moreover, they can act synergistically with other antioxidants $(1,10)$ and DHLA works to regenerate antioxidants such as ascorbate, glutathione and vitamin E (10). Therefore, LA and DHLA may play central roles in a physiological antioxidant network and are known as "universal antioxidants" (1).

In addition to its antioxidant activity, LA is known to have many physiological functions such as anti-inflammatory and immune modulation (11). It has been clinically used for many diseases or pathological conditions especially related to diabetic complex syndromes such as diabetic neuropathy in Germany (1,11-13).

LA is absorbed from the gastrointestinal tract and rapidly appears in plasma after oral administration. The plasma clearance is rather high but only 50 to $70 \%$ of the administered dose is recovered in urine as metabo- 
lites including short chain LA analogues and 1,2-dithiolane ring cleavage compounds (14). The plasma and tissue levels of free LA are known to be quite low and thus it was considered to exist in the tissues as the protein-bound form. Indeed, the tissue level of LA is usually measured as lipoyl lysine after proteolytic digestion of tissues $(9,10)$. This suggested that a significant amount of the LA-administered dose might be stored in tissues and may act as a coenzyme under physiological conditions. However, it is not known whether externally administrated LA is incorporated into protein and if so, if it is still active as an antioxidant. Also in question is if the protein bound form of LA functions as an antioxidant buffer from which free LA is supplied under oxidative stress conditions. We thus focused our attention on the role of the enzyme lipoamidase which mediates the formation and breakage of the lipoamide bond $(2,15$, 16), to determine if its activity might reflect the physiological status of LA in tissues.

We developed a new fluorescent substrate for lipoamidase, dansyl- $\alpha$-lipoyllysine (DLL), for use in a lipoamidase activity assay (17). Since the dansyl fluorophore has a better quantum yield than the previously reported probe 6-aminoquinoline, a more sensitive assay was attained using DLL as the lipoamidase substrate. Moreover, the advantage of the present method is that a simple comparison of the fluorescence intensity of dansylated lysine (DL) and DLL permitted the quantification of the enzyme activity without considering the absolute amount of DL extracted from the reaction solution. We examined the precise experimental conditions for the quantitative assay of lipoamidase activity, and applied the established method to determine the tissue distribution of lipoamidase activity.

\section{MATERIALS AND METHODS}

Chemicals and reagents. DLL and DL were synthesized and validated as previously reported (17). R-LA and S-LA as sodium salts were generously provided by Dr. Lester Packer of the University of Southern California (they were originally prepared by GeroNova Research, Inc., Richmond, CA). $N_{\varepsilon^{-}}$Acetyl-L-lysine was purchased from Sigma-Aldrich Co. (St. Louis, MO, USA). Sodium azide was purchased from Wako Pure Chemical Industries, Ltd. (Osaka, Japan). Methanol and other chemicals were purchased from Wako and all reagents were the highest reagent grade and used without further purification.

Chromatography. The HPLC system used for the analysis was a Shimadzu LC-10ADVP (Japan) equipped with an autosampler (Shimadzu SIL-10 ADVP), and a column oven (Shimadzu CTO-10ADVP). The fluorescent peaks were detected using a fluorescence detector (L-7480, Hitachi, Japan), and the data was processed by a Chromatopac C-R6A data processor (Shimadzu). A Mightysil RP-18 GP 250-4.6 (5 $\mu \mathrm{m})$ ODS column was used with a guard column. HPLC was run at a column temperature of $40^{\circ} \mathrm{C}$ using a linear gradient elution beginning from $90 \%$ of solvent A (HPLC grade pure $\mathrm{H}_{2} \mathrm{O}_{2}$ containing $0.0025 \%(\mathrm{v} / \mathrm{v}) \mathrm{TFA}$ ) to $95 \%$ of solvent
B (methanol). The fluorescent peaks of DLL and DL were recorded with an excitation wavelength of $340 \mathrm{~nm}$ and emission wavelength of $500 \mathrm{~nm}$.

Protein content. Protein content was determined using a BCA protein assay kit (Wako) using bovine serum albumin as a standard.

Preparation of tissue homogenate. All experiments were carried out in accordance with the Guidelines for Animal Experimentation issued by Niigata University of Pharmacy and Applied Life Sciences. Male Wistar rats of retired age (350 g body weight) were used for tissue homogenate preparation. After anesthetization with diethyl ether, the animals $(n=3)$ were sacrificed and a midline abdominal incision was performed; tissue samples including spleen, heart, kidney, lung, liver and brain were quickly dissected, washed in ice-cold saline and wiped on a filter paper. The tissues were chopped into approximately $0.5 \mathrm{~cm}$ square pieces, mixed together, and then stored at $-80^{\circ} \mathrm{C}$ until use. A portion of each tissue was taken and a $25 \%(\mathrm{w} / \mathrm{v})$ homogenate was prepared in cold $1 \mathrm{mM}$ sodium phosphate solution $(\mathrm{pH}$ 7.0) containing $10 \%(\mathrm{v} / \mathrm{v})$ glycerol using a glass-potter homogenizer for $20 \mathrm{~s}$ thrice. The homogenate was subjected to centrifugation for $10 \mathrm{~min}$ at 3,500 rpm (Himac CT13, Hitachi) at $4^{\circ} \mathrm{C}$ to remove cell debris, and then the protein concentration of the homogenate was determined using a BCA kit to adjust the concentration to $1 \mathrm{mg}$ protein $/ \mathrm{mL}$. The samples were stored at $-80^{\circ} \mathrm{C}$ until use.

Tissue lipoamidase activity assay. The reaction buffer used for the assay was sodium phosphate buffer $(0.1 \mathrm{M}$, $\mathrm{pH} 4.5)$ containing $1 \mathrm{mM}(452 \mathrm{mg} / \mathrm{L})$ EDTA-4Na $4 \mathrm{H}_{2} \mathrm{O}$ salt and $10 \mathrm{~mm}(781 \mathrm{mg} / \mathrm{L})$ 2-mercaptoethanol $(d=$ $1.114 \mathrm{~g} / \mathrm{mL}$ ). The lipoamidase substrate, DLL, for lipoamidase was dispersed in the above reaction buffer just before the assay to make a $100 \mu \mathrm{M}$ solution.

An aliquot $(20 \mu \mathrm{L})$ of homogenate $(20 \mathrm{mg}$ protein/ $\mathrm{mL}$ ) was mixed with $170 \mu \mathrm{L}$ of the above reaction buffer, and then incubated for $1 \mathrm{~h}$ at $37^{\circ} \mathrm{C}$ after the addition of substrate solution $(10 \mu \mathrm{L})$. After the reaction, $200 \mu \mathrm{L}$ of acetone was added to stop the reaction. The solution was put on ice for $30 \mathrm{~min}$ and then centrifuged at 8,500 rpm (Himac CT13, Hitachi) for $20 \mathrm{~min}$. An aliquot of the clear supernatant $(20 \mu \mathrm{L})$ was injected onto the HPLC system.

To confirm the reaction was really mediated by lipoamidase, the competitive effect of $N_{\varepsilon}$-acetyl-L-lysine as a substrate for the amidase reaction was examined by adding it at increasing concentrations to the above assay medium.

Preparation of a standard curve for calibration of an activity unit. To calibrate the lipoamidase activity ( $\mu \mathrm{mol}$ DL released/mg protein/h), a standard curve was prepared by correlating the net amount of DL with the observed DL/DLL fluorescent ratio. A defined concentration of DLL and elevated concentrations of DL were mixed in the reaction solution with homogenate (kidney tissue homogenate was used) and extracted with acetone immediately after the mixing. The DL/DLL fluorescence ratio determined by HPLC was correlated to 
the net amount of DL in the reaction mixture.

\section{RESULTS}

The HPLC conditions were first examined using authentic DLL and DL and the best separation was attained under the HPLC conditions described in "Materials and Methods" (Fig. 1).

Since authentic lipoamidase is not available, we first confirmed that the synthetic fluorescent substrate works using tissue lipoamidase. When the substrate was incubated with kidney homogenate for $1 \mathrm{~h}$ at $37^{\circ} \mathrm{C}$, the peak corresponding to DL increased with a concomitant decrease in the DLL peak (Fig. 1). In the absence of tissue, DLL was not converted to DL. Further, no DL production was observed when the tissue was boiled before incubation with DLL, indicating that the DL generation from DLL was mediated by an enzymatic reaction, that is, by lipoamidase in the tissue (data not shown).

The extent of DL production was correlated to the incubation time up to $2 \mathrm{~h}$ while it was markedly accelerated with longer incubation times (Fig. 2A) probably because an artificial cleavage reaction was promoted due to contaminating microbes. To support this hypothesis, the lipoamidase assay was carried out in the presence of sodium azide, which is usually used for suppressing microbial activity (18). The presence of sodium azide did not affect the activity up to $2 \mathrm{~h}$ of incubation but the activity observed at incubation times longer than $3 \mathrm{~h}$ was markedly inhibited (Fig. 2A). The same tendency was also observed with other tissues such as spleen (data not shown). Thus, it is fair to say that the reaction is not significantly affected by the contaminating microbes during the first $2 \mathrm{~h}$ of incubation. Therefore, the incubation time was selected as $1 \mathrm{~h}$ for this
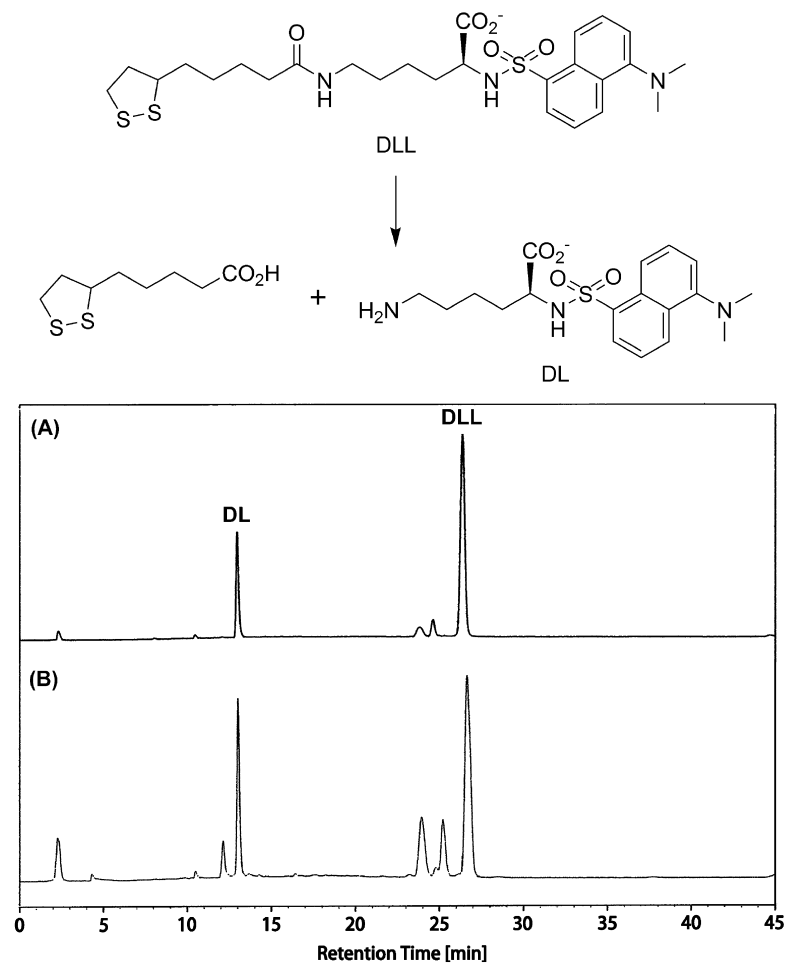

Fig. 1. The enzyme-catalyzed reaction scheme of dansyl- $\alpha$-lipoyllysine (DLL) and a typical HPLC chromatogram of (A) a standard sample containing DLL and DL in buffer, (B) the results from the reaction of DLL with rat kidney homogenate. $20 \mathrm{mg} / \mathrm{mL}$ of the tissue homogenate $(20 \mu \mathrm{L})$ was mixed with $0.1 \mathrm{mM}$ of DLL $(10 \mu \mathrm{L})$ and $100 \mathrm{~mm}$ of sodium phosphate buffer containing $1 \mathrm{mM}$ of EDTA- $4 \mathrm{Na} \cdot 4 \mathrm{H}_{2} \mathrm{O}$ salt and $10 \mathrm{mM}$ of 2 -mercaptoethanol $(170 \mu \mathrm{L})$ at $\mathrm{pH} 4.5$ and incubated for $1 \mathrm{~h}$ at $37^{\circ} \mathrm{C}$. Released DL was measured by HPLC as described in "Materials and Methods."

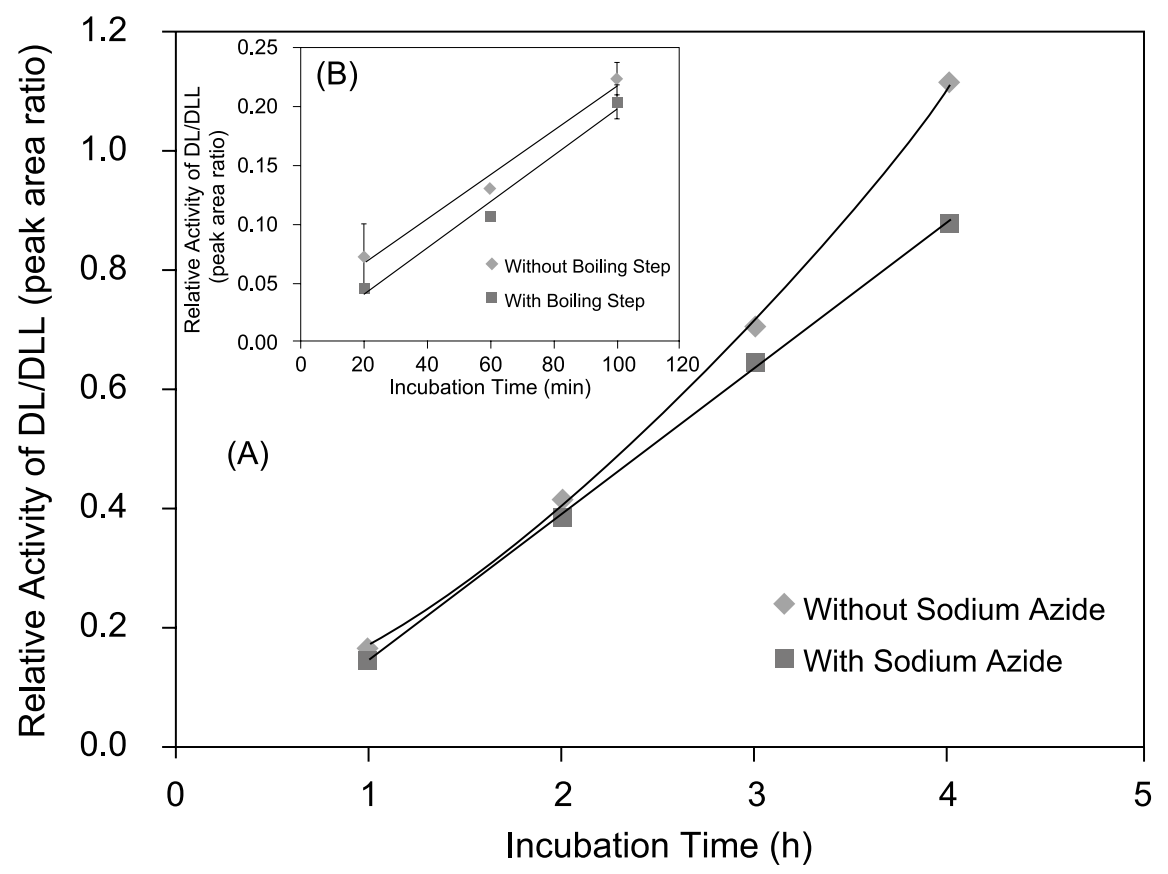

Fig. 2. Effect of incubation time on the lipoamidase reaction. The reaction mixtures were incubated with (A) kidney homogenate for 1 to $4 \mathrm{~h}$ with and without $5 \mathrm{mM}$ of sodium azide and with (B) kidney homogenate for 20 to $100 \mathrm{~min}(\mathrm{~B})$ at $37^{\circ} \mathrm{C}$ and the activities were measured as described above. All data were obtained in triplicate. 


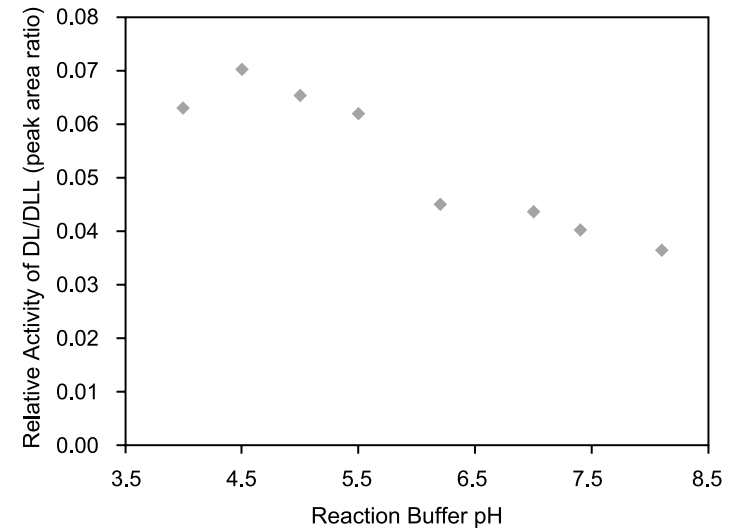

Fig. 3. pH profile of lipoamidase activity. The lipoamidase activity was determined at various $\mathrm{pHs}(\mathrm{pH} 4-8)$ in $100 \mathrm{mM}$ of sodium phosphate buffer containing $1 \mathrm{mM}$ of EDTA- $4 \mathrm{Na} \cdot 4 \mathrm{H}_{2} \mathrm{O}$ salt and $10 \mathrm{~mm}$ of 2 -mercaptoethanol $(170 \mu \mathrm{L})$ in a mixture with $20 \mathrm{mg}$ protein $/ \mathrm{mL}$ of the kidney homogenate $(20 \mu \mathrm{L})$ and $0.1 \mathrm{mM}$ of DLL $(10 \mu \mathrm{L})$. All data were obtained in triplicate.

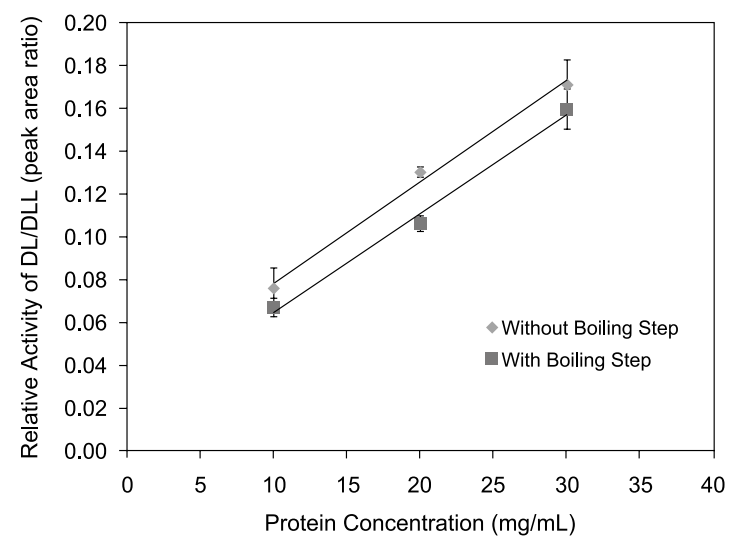

Fig. 4. Relationship between lipoamidase activity and homogenate concentration. The reaction was carried out in the presence of varying amounts of kidney homogenate for $1 \mathrm{~h}$ at $37^{\circ} \mathrm{C}$ with and without boiling the reaction mixture before acetone extraction (see "Materials and Methods"). All data were obtained in triplicate.

assay.

Next we examined the effect of $\mathrm{pH}$ on the lipoamidase reaction as shown in Fig. 3. The optimum $\mathrm{pH}$ was determined to be $\mathrm{pH} 4.5$ and then the following experiments were carried out under a buffered condition at $\mathrm{pH} 4.5$.

The DLL cleavage reaction was studied in the presence of increasing homogenate concentrations as shown in Fig. 4. The reaction was fairly dependent on the homogenate concentration between 10 and $30 \mathrm{mg}$ protein $/ \mathrm{mL}$ (Fig. 4). At concentrations higher than $30 \mathrm{mg}$ protein $/ \mathrm{mL}$, the reaction was saturated, indicating the reaction was limited by the substrate amount.

Initially, we boiled the reaction mixture to stop the enzymatic reaction before the acetone extraction of DL and DLL. However, we found that the lipoamidase reaction was not very fast and thus the recovery of DL did not vary regardless of whether we boiled the reaction

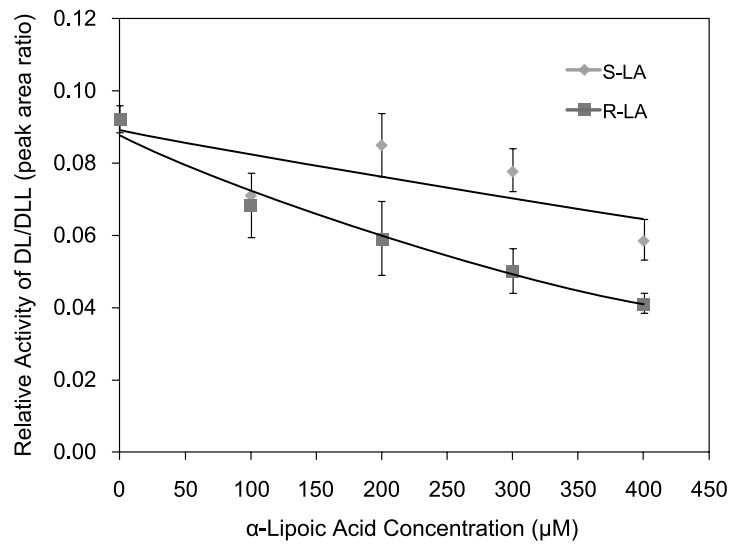

Fig. 5. Effects of R-LA and S-LA on the lipoamidase reaction. The reaction was carried out by adding increasing concentrations of either the R- or S-enantiomers of free lipoic acid (0-400 mM) using kidney homogenate. All data were obtained in triplicate.

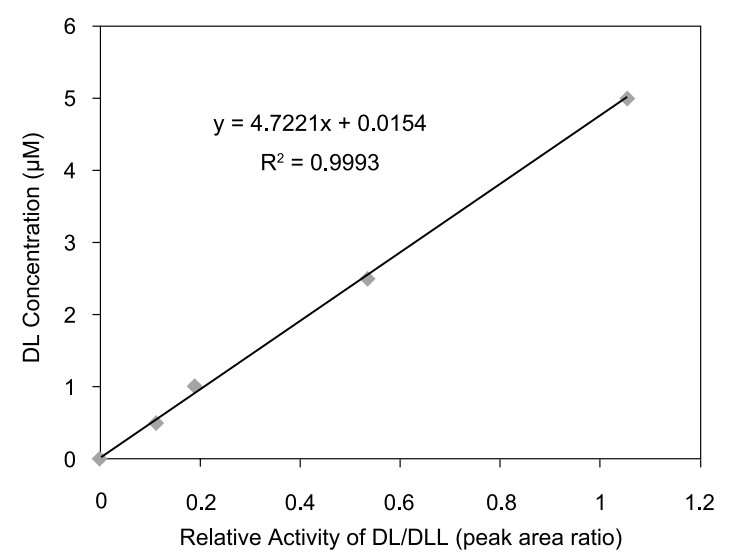

Fig. 6. Calibration curve for the determination of lipoamidase activity. A defined concentration of DLL (5 $\mathrm{mM}$ ) and elevated concentrations of DL were mixed in the reaction solution with kidney homogenate and the DL/DLL ratio was measured as described in "Materials and Methods."

mixture before extraction or not. Therefore, we omitted the boiling process in our final assay protocol. Unexpectedly, the recovery of DL was slightly increased when the boiling step was omitted as shown in Fig. 2B and Fig. 4.

For further confirmation of whether the observed release of DL from DLL was mediated by the lipoamidase reaction, we examined the effect of $N_{\varepsilon}$-acetyl-L-lysine as a competitive substrate of DLL for the amidase reaction. $N_{\varepsilon}$-acetyl-L-lysine did not affect the lipoamidase-mediated DL release from DLL (data not shown).

We also studied the effect of externally added free lipoic acid on the reaction. As the concentration of externally added lipoic acid was increased, the production of DL was inhibited in a concentration-dependent manner. Moreover, the inhibitory activity was more markedly observed in the presence of the R-enantiomer than the S-enantiomer, further indicating the observed reaction was actually mediated by the lipoamidase in 
Table 1. Lipoamidase activity of various tissues in rats.

\begin{tabular}{lcc}
\hline Tissue & $\begin{array}{c}\text { DL/DLL } \\
\text { (Ratio) }\end{array}$ & $\begin{array}{c}\text { Activity }(\mu \mathrm{mol} \mathrm{DL} \\
\text { released/mg protein } / \mathrm{h})\end{array}$ \\
\hline Spleen & $0.50 \pm 0.18$ & $0.118 \pm 0.041$ \\
Kidney & $0.22 \pm 0.020$ & $0.053 \pm 0.005$ \\
Heart & $0.20 \pm 0.14$ & $0.048 \pm 0.034$ \\
Lung & $0.15 \pm 0.01$ & $0.036 \pm 0.003$ \\
Liver & $0.02 \pm 0.006$ & $0.005 \pm 0.001$ \\
Brain & N.D. & N.D. \\
\hline
\end{tabular}

N.D., below the detection limit.

The lipoamidase activity was compared at the same protein concentration for all the tissues examined. All data were the average of three independent experiments and in each experiment the data was acquired in triplicate.

the tissue (Fig. 5).

Although a simple comparison of the fluorescence ratio of the cleaved product, DL, and the substrate, DLL, allowed us to compare the relative activity of different samples without calculating the recovery efficiency, it is more reliable to show the activity in terms of the enzymatic activity unit ( $\mu$ mole substrate hydrolyzed/mg protein/h) and thus a calibration curve was prepared using authentic DL. The activity was measured for a series of defined concentrations of DL and the DL/DLL fluorescence ratio was measured. A good correlation was obtained between the DL added and the DL/DDL ratio as shown in Fig. 6. Based on this correlation, the lipoamidase activity is calibrated from the observed DL/ DLL fluorescence ratio.

The lipoamidase activity in several organs or tissues was measured by the method established above and the results are summarized in Table 1 . It was revealed that the activity in the spleen was $0.118 \mu \mathrm{mol} / \mathrm{mg}$ protein $/ \mathrm{h}$ and was the highest among the tissues examined, followed by kidney $(0.053 \mu \mathrm{mol} / \mathrm{mg}$ protein $/ \mathrm{h})$, heart $(0.048 \mu \mathrm{mol} / \mathrm{mg}$ protein $/ \mathrm{h})$, lung $(0.036 \mu \mathrm{mol} / \mathrm{mg}$ protein $/ \mathrm{h})$ and liver $(0.005 \mu \mathrm{mol} / \mathrm{mg}$ protein $/ \mathrm{h})$. However, the activity in the brain was lower than the detection limit of the assay.

\section{DISCUSSION}

LA/DHLA has the lowest oxidation/reduction potential among the antioxidants of physiological interest and thus is implicated as an antioxidant funnel to complete the so-called antioxidant recycling system which transfers electrons to $\mathrm{NAD}(\mathrm{P}) / \mathrm{NAD}(\mathrm{P}) \mathrm{H}(10)$. Although many studies have indicated LA has a high potential for antioxidant recycling and scavenging ROS, the metabolic fate of externally consumed LA is still not fully understood. This is because orally administered LA shows only limited urinary recovery and is found at low levels in plasma (14). This suggests that LA exists in tissues primarily in the protein-bound form via an amide linkage to the $\varepsilon$-amino group of lysines in the protein $(9,10)$. However, it is not clear whether externally administered LA is incorporated into tissues as the protein-bound form and if the protein-bound form is active as an antioxidant. As lipoamidase regulates the binding and the cleavage of LA to and from the protein, it is likely that this enzyme might be involved in regulating the metabolic fate of externally administered LA. It has been reported that lipoamidase from Enterococcus faecalis catalyzes LA dissociation from lipoylated proteins (2, $15,16)$, but the role of this enzyme in LA metabolism in vertebrates has not been extensively investigated.

In the present study, we established a simple and sensitive method for measuring the lipoamidase activity in tissues using dansyl-lipoyllysine as a synthetic substrate to study the possible involvement of lipoamidase to elucidate the role of externally administrated LA (Fig. 1). A dansylated substrate provided several advantages compared to the previously reported method because the high fluorescence yield of the dansyl fluorophore improves the detection sensitivity. In addition, since the hydrolytic product, DL, is also fluorescent, a simple comparison of the DL fluorescence with that of DLL makes it possible to evaluate the lipoamidase activity without measuring the amount of DL produced (Fig. 1).

The optimum $\mathrm{pH}$ for the lipoamidase activity determined by the presently established method was $\mathrm{pH} 4.5$ (Fig. 3) which was different from that reported previously for lipoamidase determined using lipoyl-6-aminoquinoline as the substrate (19). Further it was reported the optimum $\mathrm{pH}$ of the lipoamidase isolated from $E$. faecalis was 7.8 (16). Although the reason for this discrepancy is not clear, it is interesting to note that the Renantiomer of LA was a competitive inhibitor toward the lipoamidase reaction (Fig. 5). LA comprises two enantiomeric isomers $\mathrm{R}$ and $\mathrm{S}$, and the R-isomer is the naturally occurring form, that is, the physiological isomer. This observation also supported that R-lipoic acid is a better substrate of lipoamidase in vivo and thus our observed hydrolytic cleavage of DLL into DL is likely mediated by lipoamidase in tissues. This was supported by the fact that the reaction did not occur with heattreated tissue, indicating the reaction was mediated by the enzyme (19). As well, the fact that acetyl lysine did not compete with DLL indicated the reaction is not mediated by a non-specific amidase reaction but by lipoamidase. It was notable in the present study that the DL/DLL ratio obtained without boiling was higher at any homogenate concentration than that obtained with pre-boiling (Fig. 4). The parallel shift of the dosedependent increase of the DL/DLL ratio and the homogenate concentration indicates some artificial cleavage occurred during the boiling step. Thus we decided to omit the boiling step during the tissue lipoamidase assay. In addition, the finding that the tissue lipoamidase differentiated between the $\mathrm{R}$ and $\mathrm{S}$ isomer is important because LA is usually employed as a supplement or medicine as the racemic mixture (Fig. 5). It is highly probable that lipoamidase plays a role in determining the preferential cellular uptake of the R-protein bound isomer.

When the tissue distribution of lipoamidase activity was measured by this established method, the spleen showed the highest activity, followed by the kidney, 
heart, lung and liver (Table 1). The activity in the brain was below the detection limit of the assay. The tissue distribution profile of lipoamidase activity was different from that reported previously (9) where the LA content determined as lipoyl lysine in rat tissues showed the highest value in the kidney followed by the heart, liver, spleen, brain, pancreas and lung.

The present study revealed that the tissues rich in mitochondria such as the kidney, heart and liver have proportionally higher lipoamidase activities (Table 1). This is reasonable because protein-bound LA plays an essential role in energy metabolism in mitochondria and also because lipoamidase mediates the formation and cleavage of an amide bond between LA and a protein lysine. However, as mentioned above, the activity profile of lipoamidase in tissues did not correlate well with the tissue LA levels as measured as lipoyl lysine as reported previously (9). This discrepancy suggests an alternate role of lipoamidase in LA metabolism in addition to the tissue localization of LA. Further study is required to ascertain whether lipoamidase plays an essential role in binding externally administered LA to proteins other than those of the mitochondria dehydrogenase complex and whether the protein-bound LA is still an active antioxidant. The tissue distribution profile and the assay method reported herein should prove valuable for future investigations.

\section{REFERENCES}

1) Packer L, Witt EH, Tritschler HJ. 1995. Alpha-lipoic acid as a biological antioxidant. Free Radical Biol Med 19: 227-250.

2) Koike M, Reed LJ. 1960. $\alpha$-Keto acid dehydrogenation complexes. J Biol Chem 235: 1931-1938.

3) Bradford AP, Aitken, Beg AF, Cook KG, Yeaman SJ. 1987. Amino acid sequence surrounding the lipoic acid cofactor of bovine kidney 2-oxoglutarate dehydrogenase complex. FEBS Lett 222: 211-214.

4) Fujiwara K, Okamura-Ikeda K, Motokawa Y. 1991. Lipoylation of H-protein of the glycine cleavage system. FEBS Lett 293: 115-118.

5) Attwood PV. 1995. The structure and the mechanism of action of pyruvate carboxylase. Int J Biochem Cell Biol 27: 231-249.

6) Liu SJ, Baker JC, Andrews PC, Roche TE. 1993. Recombinant expression and evaluation of the lipoyl domains of the dihydrolipoyl acetyltransferase component of the human pyruvate dehydrogenase complex. Arch Biochem
Biophys 316: 926-940.

7) Chang CF, Chou HT, Chuang JL, Chuang DT, Huang TH. 2002. Solution structure and dynamics of the lipoic acid-bearing domain of human mitochondrial branched-chain $\alpha$-keto acid dehydrogenase complex. J Biol Chem 277: 15865-15873.

8) Wollin SD, Jones PJ. 2003. $\alpha$-Lipoic acid and cardiovascular disease. J Nutr 133: 3327-3330.

9) Lodge JK, Youn HD, Handelman GJ, Konishi T, Matsugo S, Mathur VV, Packer L. 1997. Natural sources of lipoic acid: Determination of lipoyllysine released from protease-digested tissues by high performance liquid chromatography incorporating electrochemical detection. J Appl Nutr 49: 3-11.

10) Akiba S, Matsugo S, Packer L, Konishi T. 1998. Assay of protein-bound lipoic acid in tissues by a new enzymatic method. Anal Biochem 258: 299-304.

11) Yan HD, Wang Z, Chen LJ. 2009. Kinetic resolution of $\alpha$-lipoic acid via enzymatic differentiation of a remote stereocenter. J Ind Microbiol Biotechnol 36: 643-648.

12) Pruijn FB, Haenen GRMM, Bast A. 1991. Interplay between vitamin $\mathrm{E}$, glutathione and dihydrolipoic acid in protection against lipid peroxidation. Fat Sci Technol 93: 216-221.

13) Bingham PM, Zachar Z. 2000. Lipoic acid derivatives and their use in treatment of disease. International Patent. WO/2000/024734.

14) Schupke H, Hempel R, Peter RG, Hermann R, Wessel K, Engel J, Kronback T. 2001. New metabolic pathways of alpha-lipoic acid. Drug Metab Dispos 29: 855-862.

15) Reed LJ, Koike M, Levitch ME, Leach FR. 1958. Studies on the nature and reactions of protein-bound lipoic acid. J Biol Chem 232: 143-158.

16) Suzuki K, Reed LJ. 1963. Lipoamidase. J Biol Chem 238: 4021-4025.

17) Matsugo S, Wada N, Nakajima Y, Konishi T. 2008. Synthesis and application of fluorescent substrate for lipoamidase assay. J Clin Biochem Nutr 43 (Suppl 1): $468-472$.

18) Legin A, Kirsanov D, Rudnitskaya A, Iversen JJL, Seleznev B, Esbensen KH, Mortensen J, Houmøller LP, Vlasov Yu. 2004. Multicomponent analysis of fermentation growth media using the electronic tongue (ET). Talanta 64: 766-772.

19) Yoshikawa K, Hayakawa K, Katsumata N, Tanaka T, Kimura T, Kamauchi K. 1996. High-performance liquid chromatographic determination of lipoamidase (lipoyl$\mathrm{X}$ hydrolase) activity with a novel substrate, lipoyl-6aminoquinoline. J Chromatogr B Anal Technol Biomed Life Sci 679: 41-47. 